\title{
Article \\ Radio-Oxidation of Electric Cabled Models: Ageing Evaluation at the Atomic Scale
}

\author{
Muriel Ferry ${ }^{1, *}$ and Frederic Miserque ${ }^{2}$ \\ 1 Service d'Etude du Comportement des Radionucléides, Université Paris-Saclay, \\ 91191 Gif-sur-Yvette, France \\ 2 Service de la Corrosion et du Comportement des Matériaux dans leur Environnement, Université Paris-Saclay, \\ 91191 Gif-sur-Yvette, France; frederic.miserque@cea.fr \\ * Correspondence: muriel.ferry@cea.fr
}

check for updates

Citation: Ferry, M.; Miserque, F. Radio-Oxidation of Electric Cabled Models: Ageing Evaluation at the Atomic Scale. Energies 2022, 15, 1631. https://doi.org/10.3390/en15051631

Academic Editors: Simone Vincenzo Suraci, Xavier Colin and Davide Fabiani

Received: 13 January 2022 Accepted: 15 February 2022 Published: 22 February 2022

Publisher's Note: MDPI stays neutral with regard to jurisdictional claims in published maps and institutional affiliations.

Copyright: (c) 2022 by the authors. Licensee MDPI, Basel, Switzerland. This article is an open access article distributed under the terms and conditions of the Creative Commons Attribution (CC BY) license (https:// creativecommons.org/licenses/by/ $4.0 /)$.

\begin{abstract}
The functionality of electric cables, being the safety components of plants, has to be ensured. In nuclear power plants, when they are in the reactor building, these cables can suffer $\gamma$ irradiation even in normal operating conditions. Their ageing behaviour needs to be well understood to be able to determine a precise end-of-life criterion. As polymers are the most radiosensitive material of the cables, this paper focuses on the ageing of this kind of material and, more specifically, on the ageing of silane-crosslinked polyethylenes (XLPEs). XLPEs are now one of the most employed polymers to manufacture cables. We performed irradiation under oxidative conditions of several model silane-crosslinked polyethylenes with different additives and filler: at three different doses $(0$, $67,220$ and $374 \mathrm{kGy})$ for one dose rate $\left(78 \mathrm{~Gy} \cdot \mathrm{h}^{-1}\right)$ and at one dose $(67 \mathrm{kGy})$ for three dose rates (8.5, 78 and $\left.400 \mathrm{~Gy} \cdot \mathrm{h}^{-1}\right)$. Modifications in the organic materials were followed by X-ray photoelectron spectroscopy. This analytical technique allows following the evolution of the different chemical products formed under irradiation. A better understanding at the atomic scale of the effect of additives on the degradation of polymers is proposed as a function of the ageing conditions.
\end{abstract}

Keywords: formulated polyethylene; $\gamma$ irradiation; radio-oxidation; antioxidants; flame retardant; dose effect; dose-rate effect

\section{Introduction}

Whatever the industry, plants contain thousands of kilometres of electric cables of any type and size. This is also true in the case of nuclear power plants (NPPs), for which specific ageing has to be taken into account: the ageing under $\gamma$ irradiation. Cables are complex materials; each cable is composed of an electrical conductor, an insulator, a shield and a sheath. Each layer behaves differently under irradiation, with polymer parts (sheath and insulating layer) being the most vulnerable to radio-oxidation. Prediction of polymers' end-of-life criterion still remains a major challenge in the NPPs' safety [1-6].

To date, the most generally employed end-of-life criterion concerns the loss of mechanical property, often a sufficient condition to lose functional properties. Commonly, the chosen one is a failure criterion of $100 \%$ residual maximum elongation [7]. However, with the extension of the lifespan of nuclear power plants and since this type of criterion requires a large amount of aged material to be estimated, studies are now focusing on other parameters that would need a less important quantity of material but could still be related to the mechanical properties of the polymer studied. Non-exhaustively, the following parameters can be cited: electrical measurements [8,9], electron spin resonance [10-13], oxygen consumption [14], mean average molar mass [15,16] and spectroscopic measurements [17-20]. To ascertain the chosen end-of-life criterion, in-depth knowledge of the ageing mechanism must be achieved. 
Keeping this objective in mind, the purpose of this article is to obtain a deeper knowledge on polymers ageing in conditions representative of those encountered in NPPs $\left(50{ }^{\circ} \mathrm{C}\right.$ and $0.1 \mathrm{~Gy} \cdot \mathrm{h}^{-1}$ in the reactor building during normal operations). To complete a series of studies [21-27], we decided to evaluate the ageing of different silane-crosslinked polyethylenes (XLPEs) at the atomic scale. To understand the role of each additive on the ageing mechanisms, formulated model XLPEs with an increasing number of added additives and fillers were irradiated under oxidative conditions at three different doses for one dose rate and at one dose for three dose rates. X-ray photoelectron spectroscopy (XPS) was applied to determine the surface compositions of the XLPE polymers. This analytical technique is widely used to identify and quantify specific carbon forms of polymers and is complementary to other techniques, such as FTIR. Thus, in this current study, film surface analyses were performed by XPS to highlight the different chemical moieties generated during the $\gamma$ irradiation.

\section{Experimental Section}

\subsection{Materials}

Synthesis of crosslinked polyethylene XLPE has already been presented in a previous article [21]. The LLDPE chosen for this study has a density of $0.918 \mathrm{~g} \cdot \mathrm{cm}^{-3}$, a melting point of $120^{\circ} \mathrm{C}$ and contains a very small quantity of antioxidants (mainly BHT and Irganox 1076 [28]). Two antioxidants and one flame retardant were added to the XLPE during its process:

- $\quad$ primary antioxidant Irganox 1076 (chemical formula given Figure 1A)

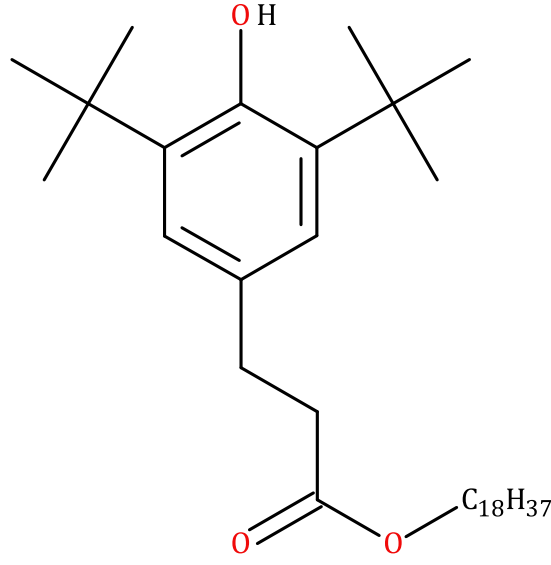

(A)

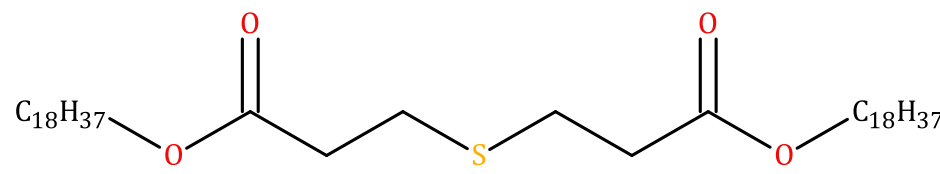

(B)

Figure 1. Chemical formula of antioxidants Irganox 1076 (A) and Irganox PS802 (B).

- $\quad$ secondary antioxidant Irganox PS802 (chemical formula given Figure 1B)

- flame retardant $\mathrm{ATH}$ (aluminium trihydrate, whose chemical formula is $\mathrm{Al}(\mathrm{OH})_{3}$ ).

The role of the primary antioxidant is to stabilise peroxide radicals [29], whereas the role of the secondary antioxidant is to reduce hydroperoxides [30]. Samples were furnished by Nexans France under the form of tapes of about $500 \mu \mathrm{m}$ thick. In this work, different formulations (with the same nomenclature as proposed in a previous paper [21]) were evaluated:

- XLPE M1: XLPE “as received"

- XLPE M2(Irg1076): XLPE + 1 phr of Irganox 1076

- XLPE M3(IrgPS802): XLPE + 1 phr of Irganox PS802

- XLPE M4(Irg1076-IrgPS802): XLPE + 1 phr of Irganox $1076+1$ phr of Irganox PS802

- XLPE M7(Irg1076-IrgPS802-ATH50): XLPE + 1 phr of Irganox $1076+1$ phr of Irganox PS802 + 50 phr of ATH 


\subsection{Irradiation Conditions}

Accelerated ageing irradiations were performed at the UJV (Rez, Czech Republic), equipped with ${ }^{60}$ Co source facilities. Depending on the required irradiation conditions, two facilities were used: Panoza and Roza. In both of them, air flows inside the irradiator chamber and the temperature is roughly constant (around $45^{\circ} \mathrm{C}$ in the case of irradiations performed in Panoza and around $21^{\circ} \mathrm{C}$ for those performed in Roza). Formulated polymer tapes were placed at a given and known distance from the source to obtain the desired dose rate, while the dose was determined using alanine dosimeters, with the uncertainty on these kinds of dosimeters being about $6.5 \%$. Table 1 sums up the irradiation conditions employed in this article. The dose effect was evaluated at a dose rate of $78 \mathrm{~Gy} \cdot \mathrm{h}^{-1}$ and using three different doses. The dose-rate effect was evaluated using three different dose rates, the common dose being equal to $67 \mathrm{kGy}$.

Table 1. Irradiation conditions employed in this work. Use of $\gamma$-rays under oxidative atmosphere.

\begin{tabular}{cccc}
\hline Facility & Panoza & Panoza & Roza \\
\hline Irradiation temperature $\left({ }^{\circ} \mathrm{C}\right)$ & 45 & 45 & 21 \\
Dose rate $\left(\mathrm{Gy} \cdot \mathrm{h}^{-1}\right)$ & 8.5 & 78 & 400 \\
Dose $(\mathrm{kGy})$ & 67 & $67,220,374$ & 67 \\
\hline
\end{tabular}

\subsection{Characterisation Using XPS}

X-ray photoelectron spectroscopy (XPS) analyses of XLPE samples were carried out with a Thermofisher Escalab 250 XI spectrometer using a monochromatic Al K $\alpha$ X-ray source. The analysis depth of the XPS technique was assumed to be between 5-10 nm depending on material density and electron kinetic energy. The instrument was calibrated in energy to the silver Fermi level $(0 \mathrm{eV})$ and to the $3 \mathrm{~d}_{5 / 2}$ core level of metallic silver $(368.3 \mathrm{eV})$, the uncertainties on peaks energy being of $0.3 \mathrm{eV}$. The samples were analysed with a dual-beam charge compensation flood gun due to the important charge effect. The C-1s signal was used to correct the charge effect; the C-C/C-H component from the XLPE on C-1s spectra was fixed at $285.0 \mathrm{eV}$. The analysis zone was a $900 \mu \mathrm{m}$ diameter spot for the monochromatic source. The pass energy for overview and high-resolution spectra was $150 \mathrm{eV}$ and $20 \mathrm{eV}$, respectively. The commercial Avantage software was used to perform data processing. For the fitting procedure, a Shirley background was used, and the Lorentzian-Gaussian $(\mathrm{L} / \mathrm{G})$ ratio was fixed at $30 \%$ for the peak shape.

Sample handling and/or surface preparation can generate carbon surface pollution. This surface pollution can present the same chemical forms as the radio-oxidative degradation product of XLPE. Due to XPS high surface sensitivity, carbon surface pollution can lead to incorrect quantification of the degradation products and/or oxygen content. Therefore, in order to remove it, argon cluster cleaning using the commercial MAGCIS ion gun was used prior to the XPS analysis. The etching conditions (etch time, cluster size and energy) were obtained thanks to the unirradiated XLPE M1 sample. Soft Ar cluster etching was performed until the minimum oxygen content was reached. $\mathrm{Ar}_{1000}$ clusters with an incident energy of $6 \mathrm{keV}$ were used for cleaning. After pollution removal, the C-1s spectrum presents a characteristic polyethylene asymmetric $\mathrm{C}-\mathrm{C}$ contribution (Figure 2A) due to vibrational fine structure, as described by Beamson and Briggs $[29,30]$. The valence band spectrum obtained (not shown) is also in good agreement (presence of two main C-2s features at 13.8 and $19.0 \mathrm{eV}$ ) with the valence band of polyethylene, as presented in the literature [31-33]. These measurements confirm that soft argon cluster etching preserves the molecular structure of polyethylene, in opposition to classical argon ion etching $\left(\mathrm{Ar}^{+}\right)$, even at low energy. Argon cluster depth profiling was also employed to evaluate the possible evaporation and/or diffusion of secondary antioxidant (Irganox PS802) following the $\mathrm{S}$ atomic concentration with depth. Unfortunately, the information on the etched depth remains qualitative, as the etching rate depends on a large number of parameters (ion energy, ion flux, density of material, etc.) and can hardly be estimated. 


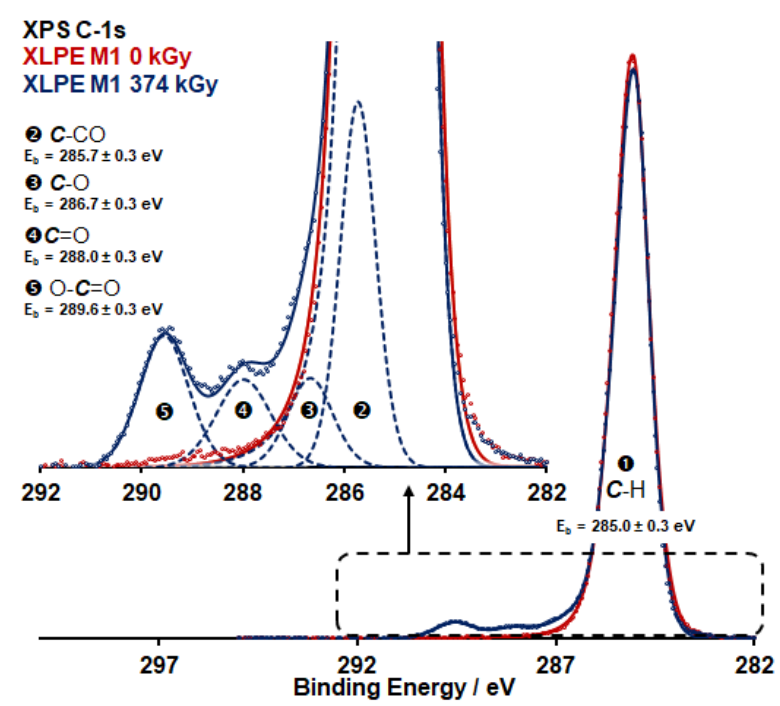

(A)

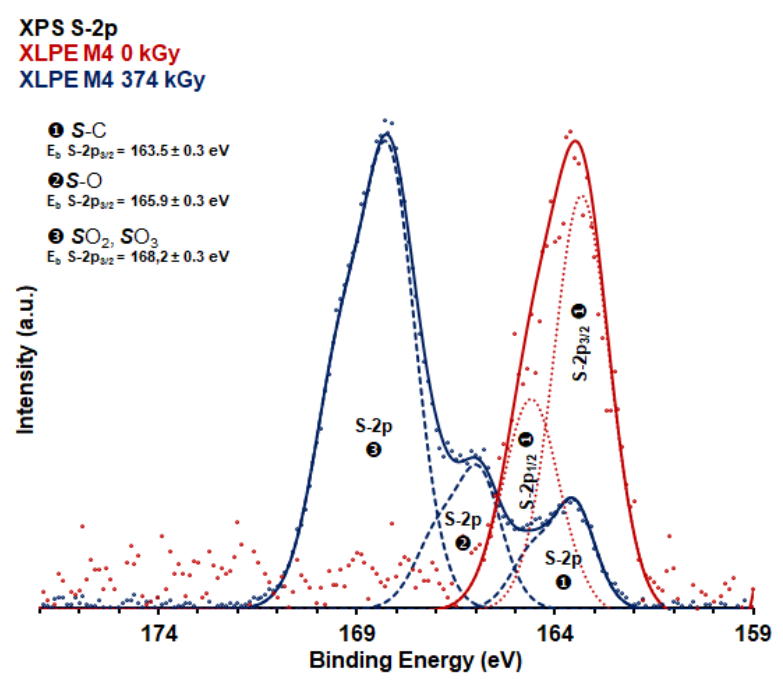

(B)

Figure 2. (A) XPS curve fitting spectra corresponding to $C$-1s spectra of XLPE M1 (non-irradiated in red and irradiated at $374 \mathrm{kGy}$ at medium dose rate in blue). Five fixed contributions were used to fit the experimental spectra: (1) $C-\mathrm{H}$ at $285.0 \pm 0.3 \mathrm{eV}$; (2) $C-\mathrm{CO}$ at $285.6 \pm 0.3 \mathrm{eV}$; (3) $C$-O at $286.9 \pm 0.3 \mathrm{eV}$; (4) $C=\mathrm{O}$ at $288.2 \pm 0.3 \mathrm{eV}$; and (5) $\mathrm{O}-C=\mathrm{O}$ at $289.5 \pm 0.3 \mathrm{eV}$. (B) XPS curve fitting spectra corresponding to $S$-2p spectra of XLPE M4(Irg1076-IrgPS802) (non-irradiated in red and irradiated at $374 \mathrm{kGy}$ at medium dose rate in blue). Three fixed contributions were employed to fit the experimental spectra: (1) C-S at $163.4 .0 \pm 0.3 \mathrm{eV}$; (2) $S=\mathrm{O}$ at $165.9 \pm 0.3 \mathrm{eV}$; and (3) $S_{2}$ and $S_{3}$ at $188.2 \pm 0.3 \mathrm{eV}$ for the $\mathrm{S}-2 \mathrm{p}_{3 / 2}$ level.

\section{Results}

Examples of the $C$-1s core-level curve fit procedure are presented in Figure 2A for XLPE M1 non-irradiated in red and irradiated at $374 \mathrm{kGy}$ at medium dose rate $\left(78 \mathrm{~Gy} \cdot \mathrm{h}^{-1}\right)$ in blue. All the spectra are presented in the Supplementary Materials (Figures S1-S16). A maximum of five fixed contributions were used to fit the experimental spectra for irradiated samples [31]: (1) $C$ - $\mathrm{H}$ at $285.0 \pm 0.3 \mathrm{eV}$, (2) $C$-CO/CO-C $=\mathrm{O}$ at $285.6 \pm 0.3 \mathrm{eV}$, (3) $C-\mathrm{O}$ at $286.9 \pm 0.3 \mathrm{eV}$, (4) $C=\mathrm{O}$ at $288.2 \pm 0.3 \mathrm{eV}$ and (5) $\mathrm{O}-C=\mathrm{O}$ at $289.5 \pm 0.3 \mathrm{eV}$. Whatever the dose, the main contribution corresponds to the peak at $285.0 \mathrm{eV}$ and is representative of the XLPE polymer. For the XLPE $C$-1s contribution, the use of only a single asymmetric lineshape rather than the use of a full (four peaks) vibrational structure was chosen. These two approaches have been found equally effective [34]. The presence of $C-\mathrm{O}, C=\mathrm{O}$ and $\mathrm{O}-C=\mathrm{O}$ components is consistent with previous XPS studies on oxidised polyethylene $[30,34,35]$. These oxidised carbon chemical products are also coherent with the radio-oxidation mechanism of polyolefin proposed by Rivaton et al. [36]. The addition of the antioxidant Irganox PS802 and its evolution with irradiation conditions can be followed by the acquisition of S-2p core levels, while for the antioxidant Irganox 1076, it is more difficult, as it has no specific elements and/or carbon chemical forms compared with irradiated XLPE. The XPS S-2p core-level spectra are presented in Figure 2B for XLPE M4(Irg1076-IrgPS802) non-irradiated in red and irradiated at $374 \mathrm{kGy}$ at a medium dose rate in blue. One contribution is observed for the non-irradiated XLPE M4(Irg1076-IrgPS802), while two additional contributions were necessary to fit the $S$ - $2 \mathrm{p}$ core-level spectrum obtained on the irradiated XLPE M4(Irg1076-IrgPS802) sample. The low binding energy $S-2 p$ contribution at $163.6 \pm 0.3 \mathrm{eV}\left(\mathrm{S}-2 \mathrm{p}_{3 / 2}\right.$ at $163.4 \pm 0.3 \mathrm{eV}$ and $\mathrm{S}-2 \mathrm{p}_{1 / 2}$ at $\left.164.6 \pm 0.3 \mathrm{eV}\right)$ is attributed at C-S-C $[31,37,38]$, consistent with the chemical formula of Irganox PS802. The two additional contributions are situated for $S-2 \mathrm{p}_{3 / 2}$ and $S-2 \mathrm{p} 1 / 2$, respectively, at 
$165.9-167.0 \mathrm{eV}$ for the second contribution and at $168.2-169.4 \mathrm{eV}$ for the third contribution. Their attributions are, respectively, sulfoxide $\mathrm{S}=\mathrm{O}$ and sulfone $\mathrm{SO}_{2}$ or sulfonate $\mathrm{SO}_{3}[37,38]$.

Carbon, oxygen and sulphur atomic relative concentrations were obviously determined. All the XLPE of this study, being crosslinked with the vinyltrimethoxysilane and XLPE M7(Irg1076-IrgPS802-ATH50) samples containing $50 \mathrm{phr}$ of ATH, Si and Al atomic concentrations in both materials, were also determined. Unfortunately, whatever the conditions, the relative atomic concentration $([\mathrm{Si}] /[\mathrm{Si}+\mathrm{C}]$ and $[\mathrm{Al}] /[\mathrm{Al}+\mathrm{C}])$ of these elements remained below 1 at. $\%$, which means that no strong surface segregation is observed for these two elements.

The results of the different relative quantifications obtained from the curve fitting procedure for the different crosslinked polyethylenes are presented in Table 2 as a function of dose rate and in Table 3 as a function of dose.

Table 2. Relative atomic ratio (at.\%) obtained from curve-fitted XPS core-level spectra ( $C$-1s, $O$-1s and S-2p) for the five XLPE materials, non-irradiated and irradiated at $67 \mathrm{kGy}$. Irradiations realised at three different dose rates, i.e., $8.5,78$ and $400 \mathrm{~Gy} \cdot \mathrm{h}^{-1}$, with $\gamma$-rays under oxidative atmosphere. $\mathrm{C}_{\mathrm{ox}}$ refers to all oxidised carbon bonds, $\mathrm{O}-\mathrm{C}=\mathrm{O}, \mathrm{C}-\mathrm{O}$ and $\mathrm{C}=\mathrm{O}$.

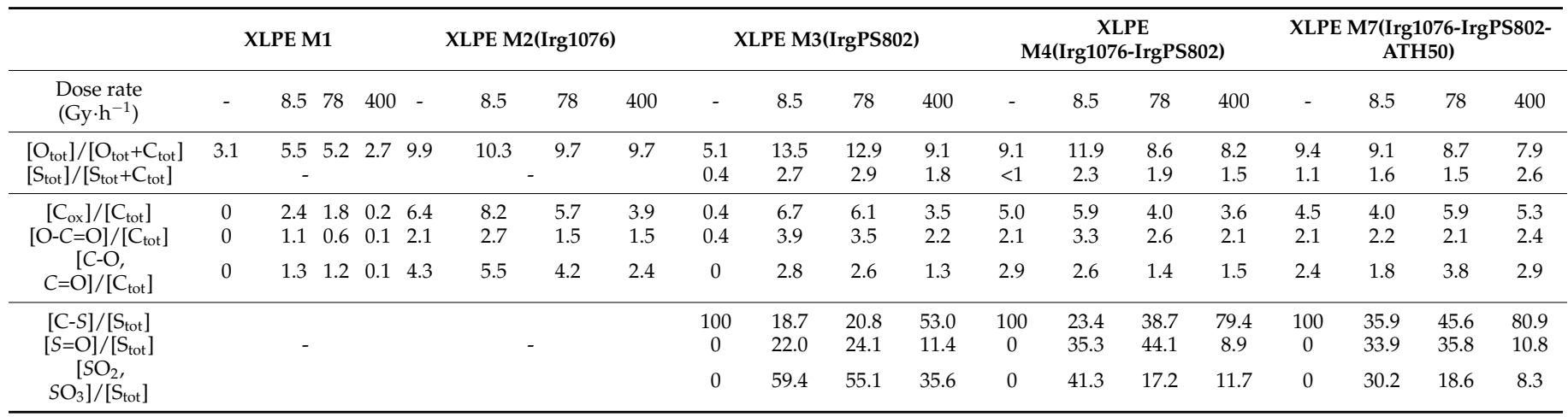

Table 3. Relative atomic ratio (at.\%) obtained from curve-fitted XPS core-level spectra $(\boldsymbol{C}-1 \mathrm{~s}, \boldsymbol{O}$ - $1 \mathrm{~s}$ and $S$-2p) for the five XLPE materials, non-irradiated and irradiated at $67 \mathrm{kGy}$, at $220 \mathrm{kGy}$ and at $374 \mathrm{kGy}$. Irradiations realised at medium dose rate $\left(78 \mathrm{~Gy} \mathrm{~h}^{-1}\right)$ with $\gamma$-rays under oxidative atmosphere. $\mathrm{C}_{\mathrm{ox}}$ refers to all oxidised carbon bonds, $\mathrm{O}-\mathrm{C}=\mathrm{O}, \boldsymbol{C}-\mathrm{O}$ and $\mathrm{C}=\mathrm{O}$.

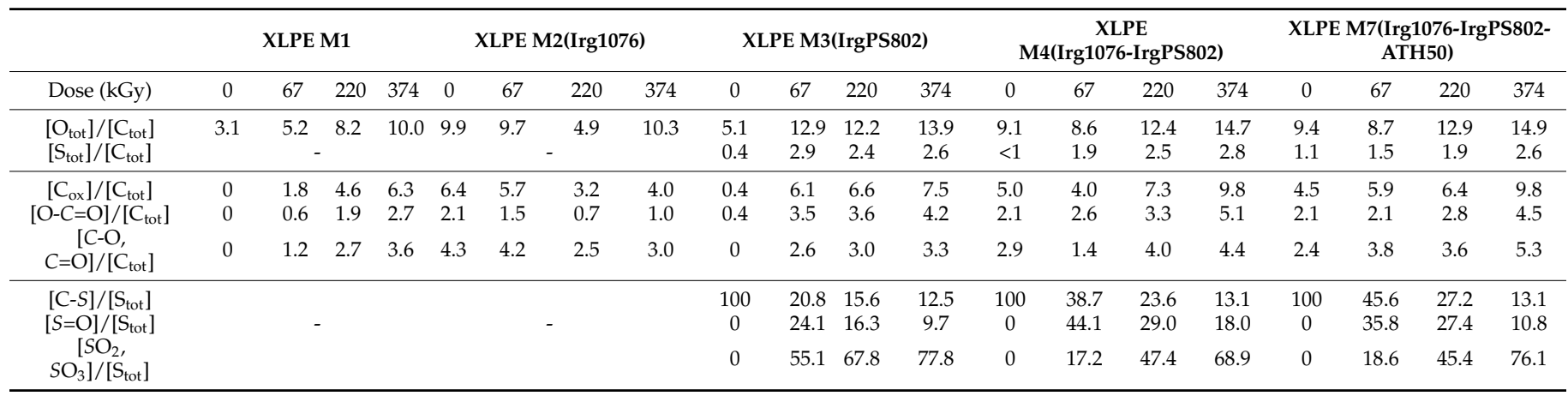

\section{Discussion}

\subsection{Dose-Rate Effect}

For sake of clarity, the relative quantifications from Table 2 are drawn on Figure 3 for the evolution of (A) $\left[C_{\mathrm{ox}}\right] /\left[\mathrm{C}_{\text {tot }}\right],(\mathrm{B})\left[\mathrm{C}_{\mathrm{O}-\mathrm{C}=\mathrm{O}}\right] /\left[\mathrm{C}_{\text {tot }}\right]$ and $(\mathrm{C})\left[S_{\mathrm{ox}}\right] /\left[\mathrm{S}_{\text {tot }}\right]$ atomic ratio as a function of the dose rate. $C_{\text {ox }}$ refers to all oxidised carbon atoms, i.e., $\mathrm{O}-\mathrm{C}=\mathrm{O}, C$-O and $C=\mathrm{O}$. 
(A)
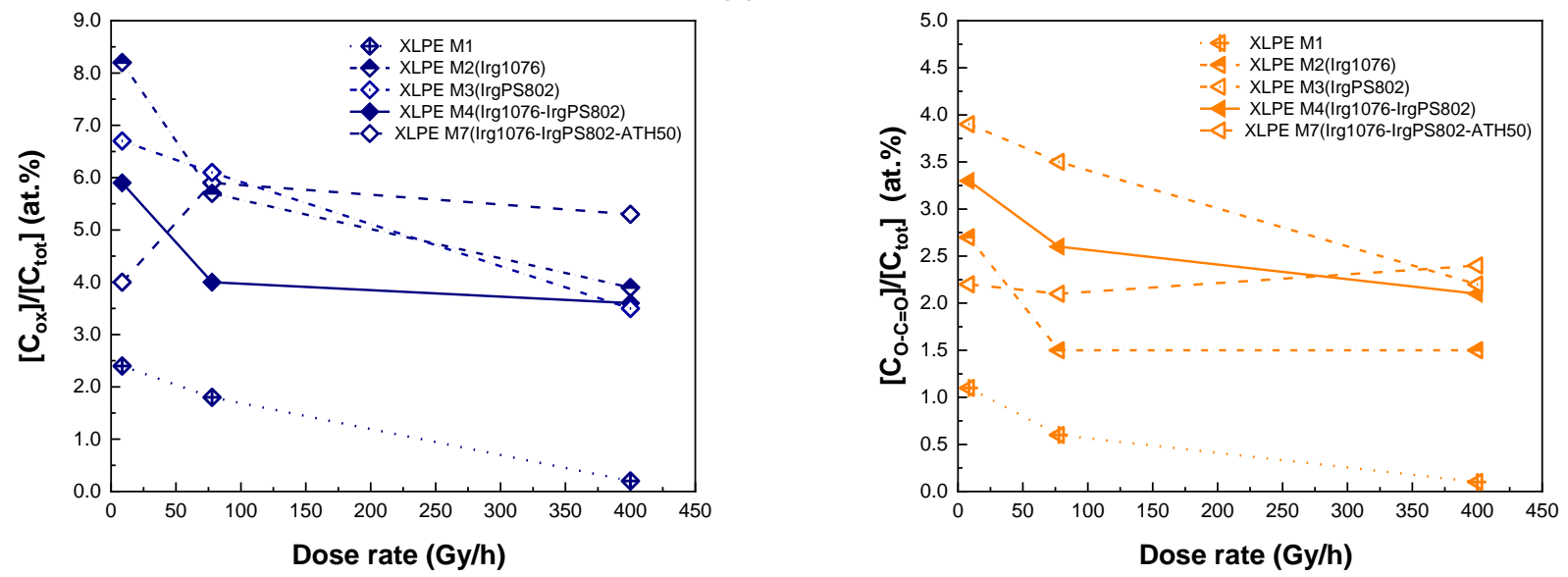

(B)

(C)

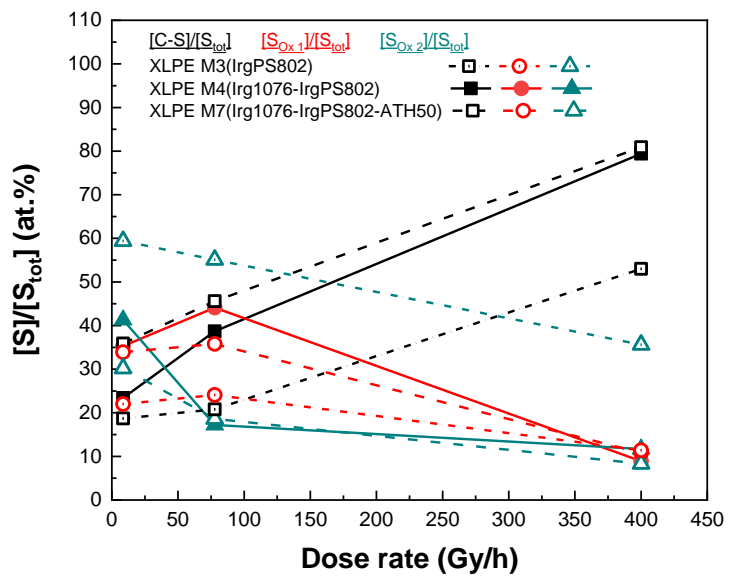

Figure 3. Evolution as a function of dose rate for XLPE M1, XLPE M2(Irg1076), XLPE M3(IrgPS802), XLPE M4(Irg1076-IrgPS802) and XLPE M7(Irg1076-IrgPS802-ATH50) of (A) $C_{\text {ox }}$, which refers to all oxidised carbon atoms (i.e., $\mathrm{O}-\boldsymbol{C}=\mathrm{O}, \boldsymbol{C}-\mathrm{O}$ and $\boldsymbol{C}=\mathrm{O}$ ) and of $(\mathbf{B}) \mathrm{O}-\boldsymbol{C}=\mathrm{O}$. Evolution as a function of dose rate for XLPE M3(IrgPS802), XLPE M4(Irg1076-IrgPS802) and XLPE M7(Irg1076-IrgPS802-ATH50) of (C) the different sulphur compounds ( $\mathrm{S}_{\mathrm{ox} 1}$ refers to $\mathrm{S}=\mathrm{O}$ and $\mathrm{S}_{\mathrm{ox} 2}$ refers to $\mathrm{SO}_{2}$ and $/$ or $\mathrm{SO}_{3}$ ).

The effect of the dose rate can be observed on the ageing of all the materials at the common dose of the evaluation of the dose-rate effect. The higher the dose rate, the lower the oxidation of the material. This kind of evolution with dose rate has already been evidenced by Decker and Mayo [39]; they have shown that the oxidation of pure polyolefin under homogeneous irradiation conditions is a function of $\frac{1}{\sqrt{d}}$, with $d$ being the dose rate in $\mathrm{Gy} \cdot \mathrm{s}^{-1}$. This evolution is because irradiation is mainly a radical formation phenomenon $\left(P H \stackrel{\gamma}{\rightarrow} P^{\circ}+H^{\circ}\right)$ and the higher the dose rate, the higher the concentration of radicals in a reduced volume. The probability of a reaction of two radicals together prior to a reaction of one radical with one $\mathrm{O}_{2}$ molecule is, thus, increasing with the dose rate, leading to a decrease in material oxidation at a high dose rate. Moreover, these radicals are reacting with $\mathrm{O}_{2}$ molecules at a rate more important than $\mathrm{O}_{2}$ diffusion in the polymer thickness; this phenomenon leading to oxygen depletion inside the material. The effect is less evident when evaluating the effect of dose rate on XLPE M2(Irg1076), XLPE M4(Irg1076-IrgPS802) and XLPE M7(Irg1076-IrgPS802-ATH50). For these materials, the oxidation decrease is also observed, but oxidised carbon concentration evolutions are scattered. This result is temptingly ascribed to a competition between consumption of the antioxidants (which initially contain $\mathrm{O}-\boldsymbol{C}=\mathrm{O} / \boldsymbol{C}$-O bonds) and oxidation of the polymer chains. For instance, at a high dose rate, the polymer oxidation is low, as is antioxidant degradation. This absence 
of a marked effect of the dose rate has already been explained in previous articles [23,25] by the fact that at the dose of the study ( $67 \mathrm{kGy})$, the formulated polymers still contain antioxidants: the effect of dose rate is delicate to evidence when an irradiated polymer is still protected by this kind of molecule.

The dose-rate effect is slightly easier to observe on the sulphur bonds evolution when Irganox PS802 is present in the polymer because oxidised S contributions present a more important variation relative to $\mathrm{C}-\mathrm{S}-\mathrm{C}$ contribution than the $C-\mathrm{O}, C=\mathrm{O}$ and $\mathrm{O}$ $\mathrm{C}=\mathrm{O}$ contributions relative to $\mathrm{C}-\mathrm{C}$ contribution ( $\mathrm{C}-\mathrm{C}$ contribution proportion remaining higher than 90 at.\% for all samples). In an equivalent way to what is observed for carbon contributions, for the lower dose rate, higher oxidation of the C-S-C is observed with an increase in the proportion of the highest oxidation degree of the sulphur atom $\left(S=\mathrm{O}, \mathrm{S}(=\mathrm{O})_{2}\right.$ ... ). Hence, whatever the XLPE under study, degradation of Irganox PS802 is also dose-rate dependent. All other conditions being equivalent, oxidation of this secondary antioxidant seems more important in XLPE M3(IrgPS802) than in XLPE M4(Irg1076-IrgPS802) and XLPE M7(Irg1076-IrgPS802-ATH50). This observation is surprising because no effect of the sole presence of the organic thiocompound has been evidenced on the oxidised carbon contributions of the crosslinked polyethylene XLPE M3(IrgPS802). It might be deduced that Irganox 1076 protects Irganox PS802. This result is surprising and has, thus, been confirmed because the reaction generally occurring between both antioxidants is a regeneration of Irganox 1076 thanks to the organic thiocompound [40].

Finally, it can be observed that the evolutions of sulphur atomic percentages are equivalent for XLPE M4(Irg1076-IrgPS802) and XLPE M7(Irg1076-IrgPS802-ATH50). As it has already been shown using high-resolution gas mass spectrometry, no effect of the ATH presence is evidenced at the chemical level on the ageing of polymer materials [21].

\subsection{Dose Effect}

As for the dose-rate effect, the relative quantification results from Table 3 are summarised on Figure 4 for the evolution of the $(\mathrm{A})\left[\mathrm{C}_{\mathrm{ox}}\right] /\left[\mathrm{C}_{\text {tot }}\right],(\mathrm{B})\left[\mathrm{C}_{\mathrm{O}-\mathrm{C}=\mathrm{O}}\right] /\left[\mathrm{C}_{\text {tot }}\right]$ and $(\mathrm{C})$ $\left[S_{\mathrm{ox}}\right] /\left[\mathrm{S}_{\text {tot }}\right]$ ratio as a function of dose. $C_{\mathrm{ox}}$ refers to all oxidised carbon atoms, i.e., O-C=O, $C-\mathrm{O}$ and $C=\mathrm{O}$.

From the oxidised carbon evolution, it can be noticed that XLPE M1 was not oxidised prior to irradiation, whereas this is not the case for XLPE M2(Irg1076), XLPE M3(IrgPS802), XLPE M4(Irg1076-IrgPS802) and XLPE M7(Irg1076-IrgPS802-ATH50). The observation of oxidised bonds in these last materials prior to irradiation can easily be attributed to both antioxidants. In the case of XLPE M1, all the different oxidised carbon contributions of the material increase with dose and then level off. This evolution has previously been observed and can be attributed to the known tendency towards saturation commonly observed in non-protected polymers irradiated at high doses and attributed to an equilibrium between bonds destroyed and created upon further irradiation [41-43]. A similar kind of evolution is evidenced for XLPE M3(IrgPS802); this polymer contains the secondary antioxidant alone, and it can be assumed that Irganox PS802 is not efficient when inserted in the material without any primary antioxidant. It can even be observed in Figure 4A,B that whatever the dose, the oxidised carbon concentration is higher for XLPE M3(IrgPS802) than for unprotected XLPE M1. This could imply a sensitisation of the polymer when organic thiocompounds are mixed. The behaviour of XLPE M2(Irg1076) is completely different. The initial O-C $\mathrm{O}$ O contribution ( $c f$. Figure $4 \mathrm{~B}$ ), which can be attributed mainly to the presence of Irganox 1076 ( $c f$. Figure 1A), decreases up to almost zero at $220 \mathrm{kGy}$; this evolution is temptingly attributable to the primary antioxidant consumption upon irradiation. If this hypothesis is correct, the slight $\mathrm{O}-\mathrm{C}=\mathrm{O}$ carbon concentration increase between 200 and $374 \mathrm{kGy}$ comes from the acceleration of the formation of highly oxidised defects when Irganox 1076 is consumed. Total oxygen concentration follows the same trend as the $\mathrm{O}-\mathrm{C}=\mathrm{O}$ ones, which implies that even at its expense, the protection conferred by this antioxidant is efficient: no or little oxidation of the polymer chains happens when Irganox 1076 is present. Evolutions of oxidised carbon are roughly the same for XLPE M4(Irg1076-IrgPS802) 
and XLPE M7(Irg1076-IrgPS802-ATH50), whereby a slight increase at low doses and an acceleration at higher doses is due to the progressive consumption of the antioxidant(s). This evolution has already been observed during the study of radiolysis gases, particularly on the evolutions of oxygen consumption and of carbon dioxide release [21].

(A)

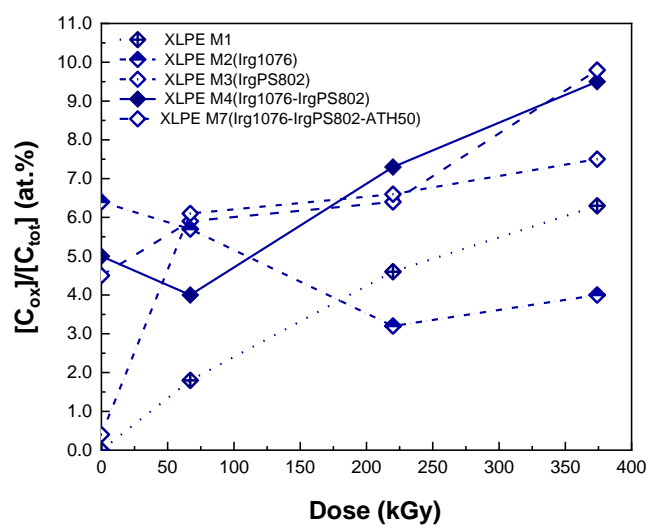

(B)

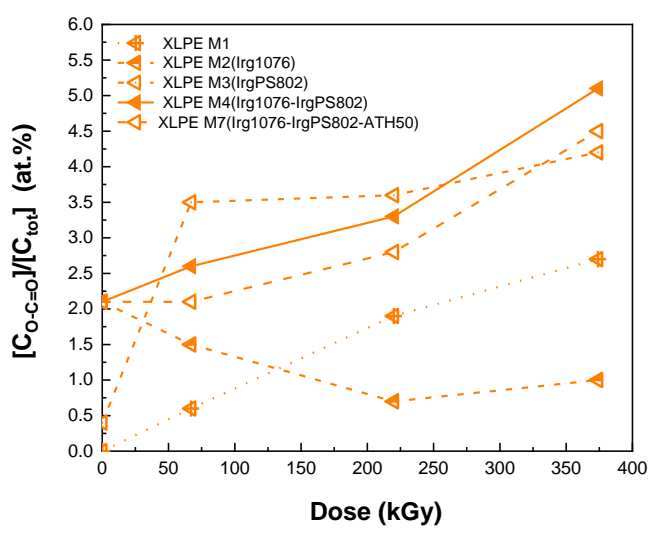

(C)

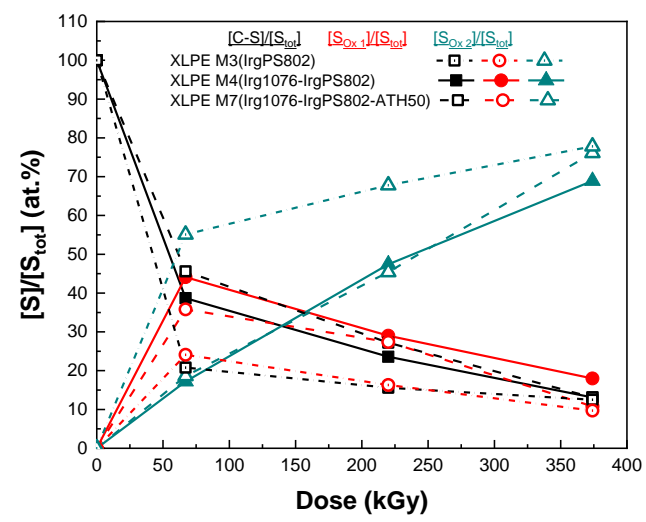

Figure 4. Evolution as a function of dose for XLPE M1, XLPE M2(Irg1076), XLPE M3(IrgPS802), XLPE M4(Irg1076-IrgPS802) and XLPE M7(Irg1076-IrgPS802-ATH50) of (A) $\boldsymbol{C}_{\mathrm{ox}}$, which refers to all oxidised carbon atoms, (i.e., $\mathrm{O}-\boldsymbol{C}=\mathrm{O}, \boldsymbol{C}-\mathrm{O}$ and $\boldsymbol{C}=\mathrm{O}$ ) and of (B) $\mathrm{O}-\boldsymbol{C}=\mathrm{O}$. Evolution as a function of dose for XLPE M3(IrgPS802), XLPE M4(Irg1076-IrgPS802) and XLPE M7(Irg1076-IrgPS802-ATH50) of (C) the different sulphur compounds $\left(\mathrm{S}_{\mathrm{ox} 1}\right.$ refers to $\mathrm{S}=\mathrm{O}$ and $\mathrm{S}_{\mathrm{ox} 2}$ refers to $\mathrm{SO}_{2}$ and/or $\left.\mathrm{SO}_{3}\right)$.

Comparison between materials is interesting too. Total oxidation is more important for XLPE M1 and XLPE M3(IrgPS802) than for XLPE M2(Irg1076), XLPE M4(Irg1076-IrgPS802) and XLPE M7(Irg1076-IrgPS802-ATH50). This observation is in concordance with the principal component analysis (PCA) realised by Maléchaux et al. [23] on the same materials, who observed that the most effective additive against radiolytic oxidative ageing is Irganox 1076. This confirms the protective effect of Irganox 1076 and maybe of Irganox PS802 if in mixture with a primary antioxidant. In this work, it has also been shown that the evolution shapes of the oxidised bonds concentration are also different between polymers as a function of dose. This observation has been explained by the absence of primary antioxidant in XLPE M1 and XLPE M3(IrgPS802), leading to an important increase followed by a tendency towards saturation with dose. When Irganox 1076 is present as in XLPE M2(Irg1076), XLPE M4(Irg1076-IrgPS802) and XLPE M7(Irg1076-IrgPS802-ATH50), the evolution of oxidized bonds with dose is showing a slow increase or even decrease. It can even be remarked that the protection conferred by Irganox 1076 seems more efficient when used solely than when used with the secondary antioxidant Irganox PS802. In fact, oxidised carbon concentration decreases when the dose increases for XLPE M2(Irg1076), whereas the concentration increases slowly at a low dose and then an acceleration is observed 
at higher doses for XLPE M4(Irg1076-IrgPS802) and XLPE M7(Irg1076-IrgPS802-ATH50) when Irganox 1076 is used in combination with Irganox PS802. The first explanation that comes to mind is an antagonistic effect between antioxidants, hindrance existing between some antioxidants [44]. Nonetheless, this hypothesis can be ruled out by results from the literature.

As expected, the different oxidation evolutions of the five XLPE materials can be linked to the absence/presence of both antioxidants. The sulphur compound content evolution has, thus, been evaluated as a function of dose in the case of XLPE containing Irganox PS802. From Table 3, it can be observed that total sulphur atom concentration increases with dose. This can be explained by the migration/evaporation of the thiodipropionate antioxidant with time, which has already been evidenced in the literature [45]. This physical phenomenon is also confirmed for our samples (see, for instance, Figure 5, where the S-atom concentration is presented for XLPE M4(Irg1076-IrgPS802) at two doses (0 and 374 kGy at the dose rate of $78 \mathrm{~Gy} \cdot \mathrm{h}^{-1}$ ) and as a function of the etching time, i.e., of the depth).

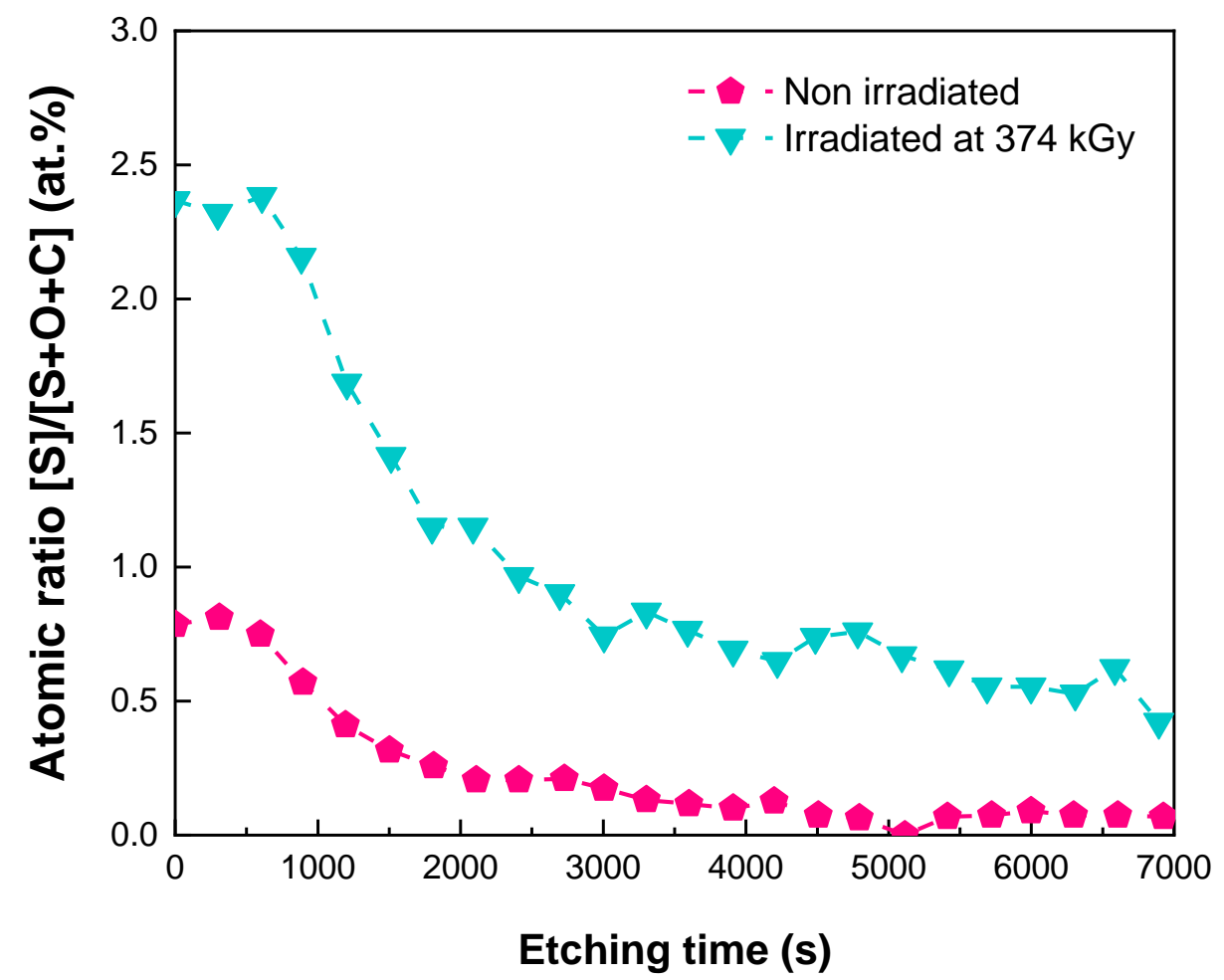

Figure 5. Sulphur relative concentration evolution for XLPE M4(Irg1076-IrgPS802) at two doses ( 0 and $374 \mathrm{kGy}$ ) and as a function of the etching time, i.e., of depth.

The total concentration of sulphur increases with dose at the surface, but the nature of the S-bond also changes ( $c f$. Figure $4 \mathrm{C}$ ). Prior to irradiation, the S-atom is obviously only linked with carbon, as it is attended for XLPE containing pristine Irganox PS802 (Figure 1B). At $67 \mathrm{kGy}$, there is an important increase in $S(=\mathrm{O})$ bonds that then decreases when the dose further increases. Finally, groups containing $\mathrm{SO}_{2}$ and $\mathrm{SO}_{3}$ increase monotonously with dose. The evolution of the S-bonds observed by XPS in this study is perfectly explained by the mechanism proposed by Richaud et al. [46] and redrawn in Figure 6. Under irradiation, Irganox PS802 is degraded, and the nature of the S-containing bonds evolve with the degradation level. 


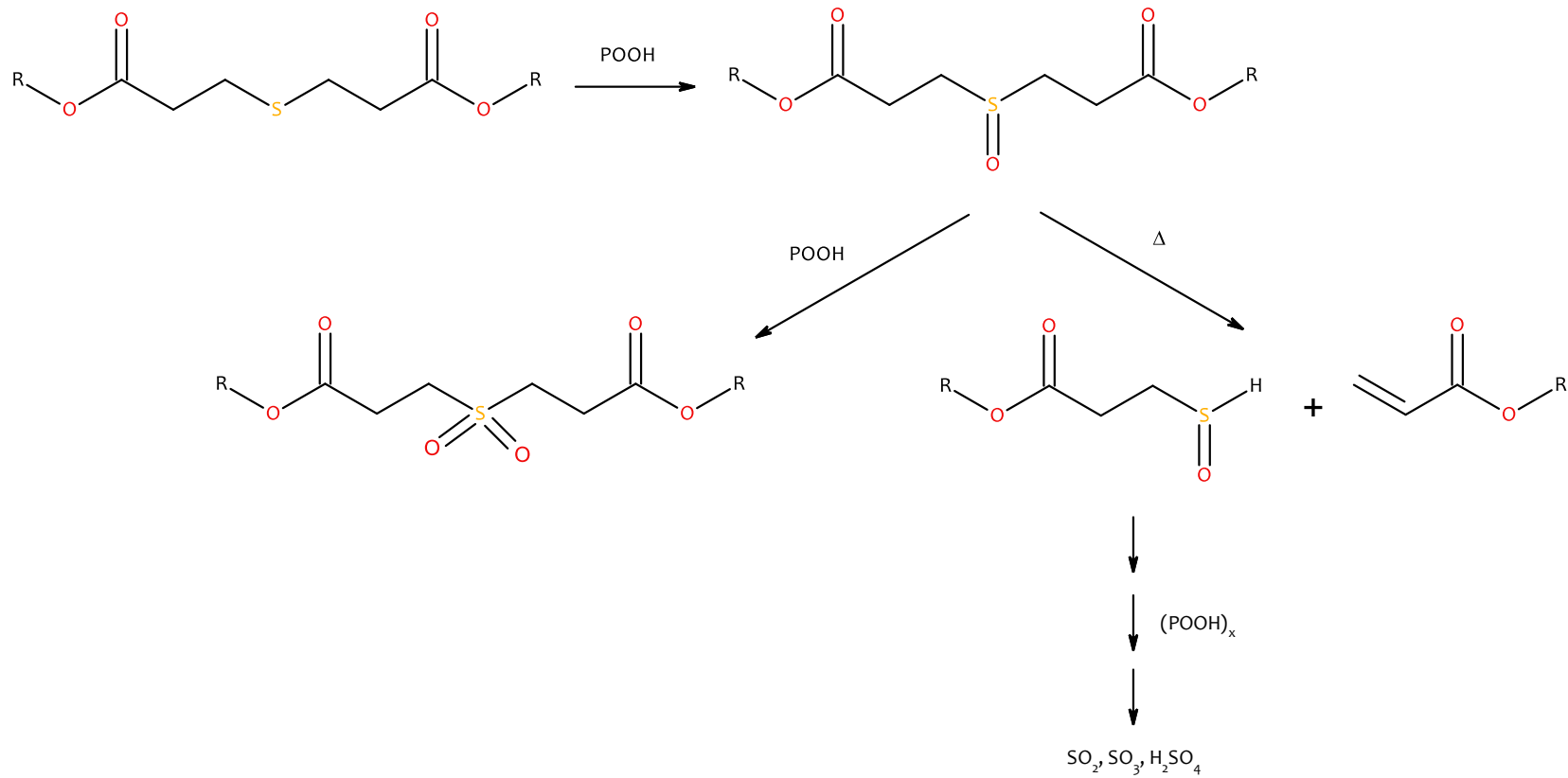

Figure 6. Schematic reactional mechanism of thioesters action, redrawn from Figure 1 of the article of Richaud et al. [46].

At $374 \mathrm{kGy}$, non-oxidised C-S-C bonds represent only 13 at.\% of sulphur in the polymer, whatever the XLPE. Knowing that there is an agglomeration of the sulphur atom at the surface of the polymer ([45] and Figure 5), it can be concluded that the concentration of remaining non-oxidised Irganox PS802 is probably even lower in material thickness. Furthermore, it has been shown in the literature [23] that localised degradation of the C-S-C bond is not the sole possible degradation pathway of organic thiocompounds. Thus, it can probably be concluded that Irganox PS802 is totally consumed at the dose of $374 \mathrm{kGy}$.

Oxidation behaviour comparison of XLPE M2(Irg1076) containing only Irganox 1076, XLPE M3(IrgPS802) containing only Irganox PS802 and of XLPE M4(Irg1076-IrgPS802) containing both antioxidants allows to have a better idea of the role and the effectiveness of both molecules. It has already been evidenced that XLPE M2(Irg1076) is very well protected by the primary antioxidant, that the polymer in XLPE M3(IrgPS802) seems sensitised by the presence of Irganox PS802 and that Irganox M4(Irg1076-IrgPS802) is well protected by both antioxidants, but with a lower efficiency compared with XLPE M2(Irg1076). Degradation of Irganox PS802 is observed whatever the sample, but the underlying mechanism seems to be without any benefice or even perhaps at the expense of the polymer. Secondary antioxidant Irganox PS802 is also called a "heat stabiliser" [23], which means that its action is known to be efficient when the temperature is relatively high, commonly about $100{ }^{\circ} \mathrm{C}$. Results presented in this article seem to simply indicate that Irganox PS802 is not efficient at the temperature of the study, that is, between $21^{\circ} \mathrm{C}$ and $47^{\circ} \mathrm{C}$. As $47^{\circ} \mathrm{C}$ is the temperature encountered in NPPs building reactors, it can be concluded that there is will no protection conferred by the presence of this molecule on the ageing of the insulating part of the cables.

Finally, an interesting point to note is that the evolutions of carbon and of sulphur atomic percentages are equivalent for XLPE M4(Irg1076-IrgPS802) and XLPE M7(Irg1076IrgPS802-ATH50) after normalisation to the organic content in the material. This confirms one of the conclusions of our previous study [21], i.e., ATH has no effect at the chemical level on the ageing of polymer materials.

\section{Conclusions}

In the context of the NPPs safety, the modifications of crosslinked polyethylenes XLPE have been evaluated upon irradiation under oxidative atmosphere. Different XLPEs were irradiated under conditions representative of the ageing in the building reactor, and the 
effect of additives and filler were assessed at the atomic scale by X-ray photoelectron spectroscopy (XPS).

Polymeric materials were irradiated at $67 \mathrm{kGy}$ and at three different dose rates. It was observed that dose-rate effect is observable for XLPE that are not protected by Irganox 1076, i.e., XLPE M1 and XLPE M3(IrgPS802), but is scattered for polymers containing this primary antioxidant, i.e., XLPE M2(Irg1076), XLPE M4(Irg1076-IrgPS802) and XLPE M7(Irg1076IrgPS802-ATH50). The secondary antioxidant degradation is dose-rate dependent and is more degraded when alone in the polymer, that is, without Irganox 1076. The interaction between polymer chains and Irganox PS802 seems to be an antagonist because XLPE M3(IrgPS802) is more degraded than XLPE M1, all other conditions being equal.

Similar XLPEs were also irradiated at different doses for one of the dose rates. It was evidenced that polymers without a primary antioxidant behave as they are not protected, while those with a primary antioxidant are protected. Surprisingly, XLPE M2(Irg1076), which contains only Irganox 1076, seems less degraded than XLPE M4(Irg1076-IrgPS802) and XLPE M7(Irg1076-IrgPS802-ATH50), which contain the secondary antioxidant too. Degradation of Irganox PS802 has been followed thanks to the S-bonds evolution, and the global oxidation of the molecule has also been evidenced but without any protection given to the polymer or maybe a slight sensitisation. Moreover, at the highest dose of the study, it is probable that there is no remaining antioxidant in the polymer, that is, neither the primary nor the secondary antioxidant.

There is no characteristic band of the primary antioxidant Irganox 1076 using XPS, and definitive conclusion on the evolution of this molecule is impossible solely with this technique; comparison with other results on similar materials and with data from the literature was of great help to determine the behaviour of this molecule during cable ageing [13,47-49]. We did not succeed to observe any benefice of the presence of the secondary antioxidant during the ageing of the cables; its role is probably on the contrary of primary importance during manufacturing. Finally, whatever the conditions employed in this study, ATH has no observable effect on the degradation of XLPE M7(Irg1076-IrgPS802ATH50) at the atomic scale.

Supplementary Materials: The following supporting information can be downloaded at: https: / /www.mdpi.com/1996-1073/15/5/1631/s1, Figure S1: $C$-1s XPS spectra of XLPE M1 irradiated at $67 \mathrm{kGy}$ and at three dose rates (i.e., 8.5, 78 and $400 \mathrm{~Gy} / \mathrm{h}$ ). Figure S2: $C$-1s XPS spectra of XLPE M1 irradiated at $78 \mathrm{kGy} / \mathrm{h}$ and at three dose $(0,67,220,374 \mathrm{kGy})$. Figure S3: $C$-1s XPS spectra of XLPE $\mathrm{M} 2$ (Irg1076) irradiated at $67 \mathrm{kGy}$ and at three dose rates (i.e., 8.5, 78 and $400 \mathrm{~Gy} / \mathrm{h}$ ). Figure S4: $C$-1s XPS spectra of XLPE M2(Irg1076) irradiated at $78 \mathrm{kGy} / \mathrm{h}$ and at three dose $(0,67,220,374 \mathrm{kGy})$. Figure S5: $C$-1s XPS spectra of XLPE M3(IrgPS802) irradiated at $67 \mathrm{kGy}$ and at three dose rates (i.e., 8.5, 78 and $400 \mathrm{~Gy} / \mathrm{h}$ ). Figure S6: C-1s XPS spectra of XLPE M3(IrgPS802) irradiated at $78 \mathrm{kGy} / \mathrm{h}$ and at three dose $(0,67,220,374 \mathrm{kGy})$. Figure S7: C-1s XPS spectra of XLPE M4(Irg1076-IrgPS802) irradiated at $67 \mathrm{kGy}$ and at three dose rates (i.e., 8.5, 78 and $400 \mathrm{~Gy} / \mathrm{h}$ ). Figure S8: $C$-1s XPS spectra of XLPE M4(Irg1076-IrgPS802) irradiated at $78 \mathrm{kGy} / \mathrm{h}$ and at three dose $(0,67,220,374 \mathrm{kGy})$. Figure S9: $C$-1s XPS spectra of XLPE M7(Irg1076-IrgPS802-ATH50) irradiated at $67 \mathrm{kGy}$ and at three dose rates (i.e., 8.5, 78 and $400 \mathrm{~Gy} / \mathrm{h}$ ). Figure S10: $C$-1s XPS spectra of XLPE M7(Irg1076-IrgPS802-ATH50) irradiated at $78 \mathrm{kGy} / \mathrm{h}$ and at three dose $(0,67,220,374 \mathrm{kGy})$. Figure S11: S-2p XPS spectra of XLPE M3(IrgPS802) irradiated at $67 \mathrm{kGy}$ and at three dose rates (i.e., 8.5, 78 and $400 \mathrm{~Gy} / \mathrm{h}$ ). Figure S12: S$2 \mathrm{p}$ XPS spectra of XLPE M3(IrgPS802) irradiated at $78 \mathrm{kGy} / \mathrm{h}$ and at three dose $(0,67,220,374$ kGy). Figure S13: S-2p XPS spectra of XLPE M4(Irg1076-IrgPS802) irradiated at $67 \mathrm{kGy}$ and at three dose rates (i.e., 8.5, 78 and $400 \mathrm{~Gy} / \mathrm{h}$ ). Figure S14: S-2p XPS spectra of XLPE M4(Irg1076-IrgPS802) irradiated at $78 \mathrm{kGy} / \mathrm{h}$ and at three dose $(0,67,220,374 \mathrm{kGy})$. Figure S15: S-2p XPS spectra of XLPE M7(Irg1076-IrgPS802-ATH50) irradiated at $67 \mathrm{kGy}$ and at three dose rates (i.e., 8.5, 78 and $400 \mathrm{~Gy} / \mathrm{h}$ ). Figure S16: S-2p XPS spectra of XLPE M7(Irg1076-IrgPS802-ATH50) irradiated at $78 \mathrm{kGy} / \mathrm{h}$ and at three dose $(0,67,220,374 \mathrm{kGy})$..

Author Contributions: Conceptualization, M.F.; methodology, F.M.; software, F.M.; validation, M.F. and F.M.; formal analysis, F.M.; investigation, M.F. and F.M.; resources, M.F. and F.M.; data curation, M.F. and F.M.; writing—original draft preparation, M.F. and F.M.; writing—review and editing, 
M.F. and F.M.; visualization, M.F. and F.M.; supervision, M.F.; project administration, M.F.; funding acquisition, M.F. All authors have read and agreed to the published version of the manuscript.

Funding: The TeaM Cables project leading to this application received funding from the Euratom Research and Training Program 2014-2018 under grant agreement no. 755183. The APC was funded by CEA.

Institutional Review Board Statement: Not applicable.

Informed Consent Statement: Not applicable.

Data Availability Statement: Not applicable.

Acknowledgments: Authors would also thank Nexans France for providing the tapes; Zuzana Sarsounova, Pavel Zak and Vit Placek from UJV (Rez, Czech Republic) for the irradiation.

Conflicts of Interest: The authors declare no conflict of interest.

\section{References}

1. Bartoníček, B.; Hnát, V.; Plaček, V. Assessment of the insulation degradation of cables used in nuclear power plants. Nucl. Instrum. Methods Phys. Res. Sect. B Beam Interact. Mater. At. 1999, 151, 423-426. [CrossRef]

2. Calmet, J.; Carlin, F.; Nguyen, T.; Bousquet, S.; Quinot, P. Irradiation ageing of CSPE/EPR control command electric cables. Correlation between mechanical properties and oxidation. Radiat. Phys. Chem. 2002, 63, 235-239. [CrossRef]

3. Dole, P.; Chauchard, J. Aging of elastomers in nuclear power plants. Effect of temperature and irradiation. Angew. Makromol. Chem. 1996, 237, 79-98. [CrossRef]

4. Reynolds, A.; Bell, R.; Bryson, N.; Doyle, T.; Hall, M.; Mason, L.; Quintric, L.; Terwilliger, P. Dose-rate effects on the radiationinduced oxidation of electric cable used in nuclear power plants. Radiat. Phys. Chem. 1995, 45, 103-110. [CrossRef]

5. $\quad$ Simmons, K.L.; Fifield, L.S.; Westman, M.P.; Ramuhalli, P.; Pardini, A.F.; Tedeschi, J.R.; Jones, A.M. Determining Remaining Useful Life of Aging Cables in Nuclear Power Plants?; Interim Study FY13; Pacific Northwest National Laboratory: Washington, DC, USA, 2013. [CrossRef]

6. Yamamoto, T.; Minakawa, T. JNES-SS-0903 Final Report of the Project of "Assessment of Cable Aging for Nuclear Power Plants"; Japan Nuclear Energy Safety Organization: Tokyo, Japan, 2009.

7. Celina, M.; George, G. Characterisation and degradation studies of peroxide and silane crosslinked polyethylene. Polym. Degrad. Stab. 1995, 48, 297-312. [CrossRef]

8. Mopsik, F.I. Radiation-induced dielectric loss in hydrocarbon polymers. J. Polym. Sci. Part B Polym. Phys. 1993, 31, 1989-1993. [CrossRef]

9. Tamblyn, J.W.; Newland, G.C. Induction period in the aging of polypropylene. J. Appl. Polym. Sci. 1965, 9, 2251-2260. [CrossRef]

10. Cracco, F.; Arvia, A.J.; Dole, M. ESR Studies of Free Radical Decay in Irradiated Polyethylene. J. Chem. Phys. 1962, 37, 2449-2457. [CrossRef]

11. Faucitano, A.; Buttafava, A.; Martinotti, F.; Ferloni, P.; Magistris, A. The mechanism of gamma-radiolysis of polymethylene, polypropylene and poly-n-butylene oxides: An ESR investigation. Int. J. Radiat. Appl. Instrum. Part C Radiat. Phys. Chem. 1992, 40, 347-355. [CrossRef]

12. Nunome, K.; Muto, H.; Toriyama, K.; Iwasaki, M. ESR studies of local concentrations of radicals in polyethylene irradiated at 1.5, 4.2 and 77 K. Chem. Phys. Lett. 1976, 39, 542-546. [CrossRef]

13. Yamazaki, T.; Seguchi, T. ESR study on chemical crosslinking reaction mechanisms of polyethylene using a chemical agent-II. The effect of phenolic antioxidants. J. Polym. Sci. Part A Polym. Chem. 1997, 35, 2431-2439. [CrossRef]

14. Gillen, K.; Bernstein, R.; Clough, R.; Celina, M. Lifetime predictions for semi-crystalline cable insulation materials: I. Mechanical properties and oxygen consumption measurements on EPR materials. Polym. Degrad. Stab. 2006, 91, 2146-2156. [CrossRef]

15. Seguchi, T.; Tamura, K.; Ohshima, T.; Shimada, A.; Kudoh, H. Degradation mechanisms of cable insulation materials during radiation-thermal ageing in radiation environment. Radiat. Phys. Chem. 2010, 80, 268-273. [CrossRef]

16. Fayolle, B.; Audouin, L.; Verdu, J. A critical molar mass separating the ductile and brittle regimes as revealed by thermal oxidation in polypropylene. Polymer 2004, 45, 4323-4330. [CrossRef]

17. Celina, M.; Gillen, K.; Wise, J.; Clough, R. Anomalous aging phenomena in a crosslinked polyolefin cable insulation. Radiat. Phys. Chem. 1996, 48, 613-626. [CrossRef]

18. Ekelund, M.; Fantoni, P.; Gedde, U. Thermal ageing assessment of EPDM-chlorosulfonated polyethylene insulated cables using line resonance analysis (LIRA). Polym. Test. 2011, 30, 86-93. [CrossRef]

19. Clough, R.L.; Gillen, K.T. Investigation of Cable Deterioration Inside Reactor Containment. Nucl. Technol. 1982, 59, 344-354. [CrossRef]

20. Papet, G.; Audouin-Jirackova, L.; Verdu, J. Diffusion controlled radiochemical oxidation of low density polyethylene-II. Kinetic modelling. Int. J. Radiat. Appl. Instrum. Part C Radiat. Phys. Chem. 1989, 33, 329-335. [CrossRef]

21. Ferry, M.; Carpentier, F.; Cornaton, M. Radio-Oxidation Ageing of XLPE Containing Different Additives and Filler: Effect on the Gases Emission and Consumption. Polymers 2021, 13, 2845. [CrossRef]

22. Hettal, S.; Roland, S.; Sipila, K.; Joki, H.; Colin, X. A new analytical model for predicting the radio-thermal oxidation kinetics and the lifetime of electric cable insulation in nuclear power plants. application to silane cross-linked polyethylene. Polym. Degrad. Stab. 2021, 185, 109492. [CrossRef] 
23. Maléchaux, A.; Colombani, J.; Amat, S.; Marque, S.; Dupuy, N. Influence of Gamma Irradiation on Electric Cables Models: Study of Additive Effects by Mid-Infrared Spectroscopy. Polymers 2021, 13, 1451. [CrossRef] [PubMed]

24. Przybytniak, G.; Sadło, J.; Walo, M. EPR studies on the interaction between additives and polyethylene matrix initiated by gamma radiation. Express Polym. Lett. 2020, 14, 556-565. [CrossRef]

25. Przybytniak, G.; Sadło, J.; Walo, M.; Wróbel, N.; Žák, P. Comparison of radical processes in non-aged and radiation-aged polyethylene unprotected or protected by antioxidants. Mater. Today Commun. 2020, 25, 101521. [CrossRef]

26. Suraci, S.V.; Fabiani, D. Aging Modeling of Low-Voltage Cables Subjected to Radio-Chemical Aging. IEEE Access 2021, 9 , 83569-83578. [CrossRef]

27. Suraci, S.V.; Fabiani, D.; Roland, S.; Colin, X. Multi scale aging assessment of low-voltage cables subjected to radio-chemical aging: Towards an electrical diagnostic technique. Polym. Test. 2021, 103, 107352. [CrossRef]

28. Xu, A.; Roland, S.; Colin, X. Physico-chemical characterization of the blooming of Irganox $1076^{\circledR}$ antioxidant onto the surface of a silane-crosslinked polyethylene. Polym. Degrad. Stab. 2019, 171, 109046. [CrossRef]

29. Beamson, G.; Clark, D.; Kendrick, J.; Briggs, D. Observation of vibrational asymmetry in the high resolution monochromatized XPS of hydrocarbon polymers. J. Electron. Spectrosc. Relat. Phenom. 1991, 57, 79-90. [CrossRef]

30. Briggs, D.; Fairley, N. XPS of chemically modified low-density polyethylene surfaces: Observations on curve-fitting the C 1s spectrum. Surf. Interface Anal. 2002, 33, 283-290. [CrossRef]

31. Beamson, G.; Briggs, D. High Resolution XPS of Organic Polymers: The Scienta Esca 300 Database; John Wiley \& Sons: Chichester, UK, 1992.

32. Buncick, M.; Thomas, D.; McKinny, K.; Jahan, M. Structural changes of ultra-high molecular weight polyethylene exposed to $\mathrm{X}$-ray flux in X-ray photoelectron spectroscopy detected by valence band and electron spin resonance spectroscopy. Appl. Surf. Sci. 2000, 156, 97-109. [CrossRef]

33. Delhalle, J.; André, J.M.; Pireaux, J.J.; Caudano, R.; Verbist, J.J. Electronic structure of polyethylene: Theory and ESCA measurements. J. Chem. Phys. 1974, 60, 595-600. [CrossRef]

34. Briggs, D.; Brewis, D.M.; Dahm, R.H.; Fletcher, I.W. Analysis of the surface chemistry of oxidized polyethylene: Comparison of XPS and ToF-SIMS. Surf. Interface Anal. 2003, 35, 156-167. [CrossRef]

35. Holländer, A.; Klemberg-Sapieha, J.E.; Wertheimer, M.R. Vacuum-ultraviolet induced oxidation of the polymers polyethylene and polypropylene. J. Polym. Sci. Part A Polym. Chem. 1995, 33, 2013-2025. [CrossRef]

36. Rivaton, A.; Cambon, S.; Gardette, J.L. Radiochemical ageing of EPDM elastomers. 3. Mechanism of radiooxidation. Nucl. Instrum. Methods Phys. Res. Sect. B Beam Interact. Mater. At. 2005, 227, 357-368. [CrossRef]

37. Siow, K.S.; Britcher, L.; Kumar, S.; Griesser, H.J. XPS Study of Sulfur and Phosphorus Compounds with Different Oxidation States. Sains Malays. 2018, 47, 1913-1922.

38. Siow, K.S. Plasma Based Methods for Producing Controlled Polymer Surfaces with Sulfur and Phosphorus Containing Chemical Groups and Interactions Between Such Surfaces and Proteins; Ian Wark Research Institute: Adelaide, SA, Australia, 2007; unpublished.

39. Decker, C.; Mayo, F.R. Aging and degradation of polyolefins. II. g-initiated oxidations of atactic polypropylene. J. Polym. Sci. 1973, 11, 2847. [CrossRef]

40. Pospísil, J. The key role of antioxidant transformation products in the stabilization mechanisms-A critical analysis. Polym. Degrad. Stab. 1991, 34, 85-109. [CrossRef]

41. Ferry, M.; Bessy, E.; Harris, H.; Lutz, P.J.; Ramillon, J.-M.; Ngono-Ravache, Y.; Balanzat, E. Aliphatic/ Aromatic Systems under Irradiation: Influence of the Irradiation Temperature and of the Molecular Organization. J. Phys. Chem. B 2013, 117, 14497-14508. [CrossRef]

42. Ferry, M.; Ramillon, J.; Been, T.; Lutz, P.; Ngono-Ravache, Y.; Balanzat, E. Energy migration effect on the formation mechanism of different unsaturations in ethylene/styrene random copolymers. Polym. Degrad. Stab. 2018, 160, 210-217. [CrossRef]

43. Ferry, M.; Pellizzi, E.; Boughattas, I.; Fromentin, E.; Dauvois, V.; de Combarieu, G.; Coignet, P.; Cochin, F.; Ngono-Ravache, Y.; Balanzat, E.; et al. Effect of cumulated dose on hydrogen emission from polyethylene irradiated under oxidative atmosphere using gamma rays and ion beams. Radiat. Phys. Chem. 2016, 118, 124-127. [CrossRef]

44. Kikkawa, K.; Nakahara, Y.; Ohkatsu, Y. Antagonism between hindered amine light stabilizers and sulfur-containing compounds Polym. Degrad. Stab. 1987, 18, 237-245. [CrossRef]

45. Xu, A.; Roland, S.; Colin, X. Thermal ageing of a silane-crosslinked polyethylene stabilised with a thiodipropionate antioxidant. Polym. Degrad. Stab. 2020, 181, 109276. [CrossRef]

46. Richaud, E.; Monchy-Leroy, C.; Colin, X.; Audouin, L.; Verdu, J. Kinetic modelling of stabilization coupled with stabilizer loss by evaporation. Case of dithioester stabilized polyethylene. Polym. Degrad. Stab. 2009, 94, 2004-2014. [CrossRef]

47. Allen, N.S.; Edge, M. Perspectives on additives for polymers. Part 2. Aspects of photostabilization and role of fillers and pigments. J. Vinyl Addit. Technol. 2020, 27, 211-239. [CrossRef]

48. Allen, S.N.; Edge, M. Perspectives on additives for polymers. 1. Aspects of stabilization. J. Vinyl Addit. Technol. 2020, 27, 5-27. [CrossRef]

49. Beißmann, S.; Reisinger, M.; Grabmayer, K.; Wallner, G.; Nitsche, D.; Buchberger, W. Analytical evaluation of the performance of stabilization systems for polyolefinic materials. Part I: Interactions between hindered amine light stabilizers and phenolic antioxidants. Polym. Degrad. Stab. 2014, 110, 498-508. [CrossRef] 